the entire study period (mean $[ \pm S D]$ exposure to secukinumab of $1025.1 \pm 372.7$ days), the exposure-adjusted incidence rate with secukinumab for serious infections/infestations, candida infections, Crohn's disease, and malignant/unspecified tumors was 1.7 (27), 1.2 (17), 0.1 (2), and 0.9 (14) per 100 pt-yrs, respectively. Conclusions: Secukinumab provided sustained improvements in signs/symptoms and across multiple clinical domains of active PsA in pts who completed $3 \mathrm{yrs}$ of therapy. Secukinumab was well tolerated with a favorable safety profile consistent with that previously reported. ${ }^{1}$

References:

[1] Kavanaugh A, et al. Arthritis Care Res. (Hoboken) 2016

Disclosure of Interest: P. Mease Grant/research support from: Abbvie, Amgen, BMS, Celgene, Crescendo Bioscience, Genentech, Janssen, Lilly, Merck, Novartis, Pfizer, UCB, Consultant for: Abbvie, Amgen, BMS, Celgene, Crescendo Bioscience, Genentech, Janssen, Lilly, Merck, Novartis, Pfizer, UCB, Speakers bureau: Abbvie, Amgen, BMS, Celgene, Crescendo Bioscience, Genentech, Janssen, Lilly, Merck, Novartis, Pfizer, UCB, A. Kavanaugh Consultant for: Novartis, A. Reimold Grant/research support from: AbbVie, H. Tahir Speakers bureau: Novartis, Eli Lilly, and Abbvie, J. Rech Speakers bureau: Abbvie, BMS, Celgene, Fresenius, medicap, MSD, Novartis, Pfizer, and Roche, S. Hall: None declared, P. Geusens Grant/research support from: Pfizer, Abbott, Lilly, Amgen, MSD, Will, Bio Minerals and Roche, Speakers bureau: Pfizer, Abbott, Lilly, Amgen, MSD, Will, Bio Minerals and Roche, P. Pascale Shareholder of: Novartis, Employee of: Novartis, E. M. Delicha Employee of: Novartis, L. Pricop Shareholder of: Novartis, Employee of: Novartis, S. Mpofu Shareholder of: Novartis, Employee of: Novartis DOI: 10.1136/annrheumdis-2017-eular.1260

\section{SAT0471 TRENDS IN CLINICAL CHARACTERISTICS ASSOCIATED WITH ACHIEVEMENT OF MINIMAL DISEASE ACTIVITY IN RESPONSE TO BIOLOGIC THERAPY IN PSORIATIC ARTHRITIS - ANALYSES FROM THE CORRONA PSORIATIC ARTHRITIS/SPONDYLOARTHRITIS (PSA/SPA) REGISTRY}

P.J. Mease ${ }^{1}$, C. Karki ${ }^{2}$, M. Liu ${ }^{2}$, A. Kavanaugh ${ }^{3}$, C.T. Ritchlin ${ }^{4}$, D.H. Hunyh ${ }^{5}$, R. Pandurengan ${ }^{2}$, J.B. Palmer ${ }^{6}$, J.D. Greenberg $2,7 .{ }^{1}$ Seattle Rheumatology Associates, Seattle, WA; ${ }^{2}$ Corrona, LLC, Southborough, MA; ${ }^{3}$ University of California San Diego, San Diego, CA: ${ }^{4}$ University of Rochester, Rochester, NY; ${ }^{5}$ Scripps Institute, la Jolla, CA; ${ }^{6}$ Novartis, East Hanover, $\mathrm{NJ} ;{ }^{7}$ New York University School of Medicine, New York, NY, United States

Background: Achievement of minimal disease activity (MDA) may represent an objective target for treatment for patients with psoriatic arthritis (PsA). ${ }^{1}$ A patient is considered to have achieved MDA when 5 of the following 7 criteria are met: tender joint count (TJC) $\leq 1$, swollen joint count (SJC) $\leq 1$, affected body surface area $(B S A) \leq 3 \%$, patient pain VAS $\leq 15$, patient global activity VAS $\leq 20, \mathrm{HAQ}$ score $\leq 0.5$ and tender entheseal points $\leq 1 .{ }^{1}$

Objectives: To retrospectively report the MDA and patient-reported outcomes (PROs) over time (baseline vs first follow-up [FU] visit vs second FU visit) that may contribute to achievement of MDA in responders versus non-responders to biologic treatment.

Methods: This analysis included all patients with PsA in the Corrona registry aged $\geq 18$ years between March 2013 and March 2016 who received biologics (index biologics) at enrollment (baseline) and had $\geq 2 \mathrm{FU}$ visits (at $\approx 6$-month intervals, mean [SD] 2nd FU visit: 15.7 [3.7] months). Responders were defined as patients who achieved MDA at the second FU visit and remained on their index biologic. Demographics, clinical characteristics, PROs and treatment history were collected at enrollment and at both FU visits. Trend tests of MDA over time were performed using the Wilcoxon rank-sum nonparametric test for responders and non-responders separately.

Results: Of 148 patients who met the inclusion criteria (mean [SD] age, 54.7 [11.0] years; mean [SD] disease duration, 11.8 [10.1] years), 34 patients (23\%) were classified as responders and 114 patients $(77 \%)$ were non-responders at the second FU visit. The core components of MDA in these patients are shown in Table 1. Among responders, there were significant improvements in clinical characteristics and PROs such as mean TJC ( 3.4 vs 2.1 vs $0.6 ; P=0.004$ ), SJC (2.5 vs 0.8 vs $0.5 ; P<0.0001)$, percentage of affected BSA $(5.6 \%$ vs $2.4 \%$ vs $1.4 \% ; P=0.03)$, patient pain (34.7 vs 26.1 vs $21.9 ; P=0.007)$ and HAQ scores $(0.6$ vs 0.4 vs $0.3 ; P=0.04)$; however, there were no significant changes over time for patient global assessment or enthesitis counts $(P>0.05)$. Non-responders failed to have a significant improvement from baseline to the first and second FU visits in TJC, SJC, enthesitis, pain, patient global assessment and percentage of affected BSA (all $P>0.05$ )

Conclusions: Only $23 \%$ of patients achieved MDA on their index biologic at the second FU visit and were considered responders. Over time, responders showed significant improvements in TJC and SJC, percentage of affected BSA, patient pain and HAQ scores; these most likely contributed to achievement of MDA response. A treat-to-target approach may be considered given the low number of patients in MDA.

References:

[1] Coates, LC et al. Ann Rheum Dis. 2010;69(1):48-53.

Acknowledgements: Corrona, LLC, has been supported through contracted subscriptions in the last 2 years by AbbVie, Amgen, BMS, Crescendo, Eli Lilly and Company, GSK, Horizon Pharma USA, Janssen, Momenta Pharmaceuticals, Novartis, Pfizer, Roche and UCB.
Table 1. Clinical and patient-reported characteristics of patients with PsA in the Corrona registry stratified by response to index biologics over time

\begin{tabular}{|c|c|c|c|c|c|c|c|c|}
\hline \multirow[b]{2}{*}{ Characteristics $^{*}$} & \multicolumn{2}{|c|}{ At Enrollment } & \multicolumn{2}{|c|}{ 1st FU Visit } & \multicolumn{2}{|c|}{ 2nd FU Visit } & \multirow{2}{*}{$\begin{array}{c}P \\
\text { Value } \\
(R)\end{array}$} & \multirow{2}{*}{$\begin{array}{c}P \\
\text { Value } \\
\text { (NR) }\end{array}$} \\
\hline & $\begin{array}{c}R \\
n=34\end{array}$ & $\begin{array}{c}N R \\
n= \\
114\end{array}$ & $\begin{array}{c}R \\
n=34\end{array}$ & $\begin{array}{l}N R \\
n= \\
114\end{array}$ & $\begin{array}{c}R \\
n=34\end{array}$ & $\begin{array}{l}N R \\
n= \\
114\end{array}$ & & \\
\hline MDA, $n(\%)^{\dagger}$ & $\begin{array}{l}0 \\
\text { (0) }\end{array}$ & $\begin{array}{l}0 \\
0 \\
(0)\end{array}$ & $\begin{array}{c}17 \\
(57)\end{array}$ & $\begin{array}{c}13 \\
(14)\end{array}$ & $\begin{array}{c}34 \\
(100)\end{array}$ & $\begin{array}{c}10 \\
(8.8)\end{array}$ & $\begin{array}{c}< \\
0.0001\end{array}$ & 0.01 \\
\hline $\begin{array}{l}\text { Tender joint count (0- } \\
68 \text { ) }\end{array}$ & $\begin{array}{l}3.4 \\
(5.3)\end{array}$ & $\begin{array}{c}7.2 \\
(11.0)\end{array}$ & $\begin{array}{c}2.1 \\
(5.1)\end{array}$ & $\begin{array}{l}6.0 \\
(8.2)\end{array}$ & $\begin{array}{c}0.6 \\
0.4)\end{array}$ & $\begin{array}{c}6.6 \\
(11.7)\end{array}$ & 0.004 & 0.16 \\
\hline $\begin{array}{l}\text { Swollen joint count (0- } \\
66 \text { ) }\end{array}$ & $\begin{array}{l}2.5 \\
(3.5)\end{array}$ & $\begin{array}{l}2.8 \\
(3.7)\end{array}$ & $\begin{array}{c}0.8 \\
(1.7)\end{array}$ & $\begin{array}{l}2.5 \\
(4.5)\end{array}$ & $\begin{array}{c}1.7) \\
0.5 \\
(1.5)\end{array}$ & $\begin{array}{l}2.3 \\
(3.9)\end{array}$ & $\begin{array}{c}< \\
0.0001\end{array}$ & 0.12 \\
\hline $\begin{array}{l}\text { SPARCC enthesitis (0- } \\
16 \text { ) }\end{array}$ & $\begin{array}{l}2.01 \\
2.4 \\
(0.5)\end{array}$ & $\begin{array}{l}(3.1) \\
4.4 \\
(3.3)\end{array}$ & $\begin{array}{l}3.1) \\
3.0 \\
(2.8)\end{array}$ & $\begin{array}{l}(7.0) \\
4.1 \\
(3.3)\end{array}$ & $\begin{array}{l}(1.0) \\
(1.4)\end{array}$ & $\begin{array}{l}3.97 \\
(1.9)\end{array}$ & 0.70 & 0.67 \\
\hline BSA, $\%$ & 5.6 & $\begin{array}{c}8.3 \\
14.4)\end{array}$ & 2.4 & 5.1 & 1.4 & 4.8 & 0.03 & 0.006 \\
\hline $\begin{array}{l}\text { Patient-reported pain } \\
\text { (VAS } 0-100 \text { ) }\end{array}$ & $\begin{array}{l}35.7 \\
(23.4)\end{array}$ & $\begin{array}{l}51.2 \\
(24.8)\end{array}$ & $\begin{array}{l}26.1 \\
(25.2)\end{array}$ & $\begin{array}{l}54.6 \\
(26.3)\end{array}$ & $\begin{array}{c}21.9 \\
(20.5)\end{array}$ & $\begin{array}{l}54.6 \\
(25.3)\end{array}$ & 0.007 & 0.28 \\
\hline $\begin{array}{l}\text { Patient global } \\
\text { assessment (VAS 0- } \\
100 \text { ) }\end{array}$ & $\begin{array}{c}70 \\
(17.8)\end{array}$ & $\begin{array}{l}53.6 \\
(24.0)\end{array}$ & $\begin{array}{l}59.2 \\
(30.2)\end{array}$ & $\begin{array}{l}54.3 \\
(24.5)\end{array}$ & $\begin{array}{c}62 \\
(31.4)\end{array}$ & $\begin{array}{l}(20.0) \\
(22.5)\end{array}$ & 0.58 & 0.47 \\
\hline $\operatorname{HAQ}(0-3)$ & $\begin{array}{l}0.6 \\
(0.5)\end{array}$ & $\begin{array}{l}1.0 \\
(0.6)\end{array}$ & $\begin{array}{c}0.4 \\
(0.5)\end{array}$ & $\begin{array}{l}1.0 \\
(0.6)\end{array}$ & $\begin{array}{c}0.3 \\
(0.4)\end{array}$ & $\begin{array}{l}1.0 \\
(0.6)\end{array}$ & 0.04 & 0.54 \\
\hline
\end{tabular}

BSA, body surface area; FU, follow-up: $H A Q$, Health Assessment Questionnaire; MDA, minimal disease activity; NR, non-responders; R, responders; SPARCC, Spondyloarthritis Research Consortium of Canada; VAS, visual analog scale. "All values are presented as "mean (SD)" unless otherwise stated. gories tender joint count $\leq 1$, swollen joint count $\leq 1$
points $\leq 1$

Disclosure of Interest: P. Mease Grant/research support from: Celgene, Novartis, AbbVie, Amgen, BMS, Lilly, Pfizer, UCB, Consultant for: Celgene, Corrona, Novartis, AbbVie, Amgen, BMS, Crescendo, Genentech, Janssen, Lilly, Merck, Pfizer, UCB, C. Karki Employee of: Corrona, LLC, M. Liu Employee of: Corrona, LLC, A. Kavanaugh Grant/research support from: Amgen, AbbVie, Janssen, Pfizer, Novartis, C. Ritchlin Grant/research support from: Amgen, Janssen, UCB, Consultant for: AbbVie, Amgen, Janssen, Regeneron, UCB, D. Hunyh Speakers bureau: AbbVie, BMS, R. Pandurengan Employee of: Corrona, LLC, J. Palmer Employee of: Novartis, J. Greenberg Shareholder of: Corrona, LLC, Consultant for: Lilly, Genentech, Janssen, Novartis, Pfizer, Employee of: Corrona, LLC DOI: 10.1136/annrheumdis-2017-eular.1479

\section{SAT0472 UTILIZATION OF THE PSORIASIS EPIDEMIOLOGY SCREENING TOOL TO IDENTIFY SIGNS AND SYMPTOMS OF EARLY PSORIATIC ARTHRITIS AMONG THOSE WITH PSORIASIS: ANALYSIS FROM THE CORRONA PSORIASIS REGISTRY}

P.J. Mease ${ }^{1}$, J.B. Palmer ${ }^{2}$, M. Lebwohl ${ }^{3}$, C. Karki ${ }^{4}$, G.W. Reed ${ }^{4,5}$, C.J. Etzel ${ }^{4,6}$ J.D. Greenberg ${ }^{4,7}$, P.S. Helliwell ${ }^{8} .{ }^{1}$ Swedish Medical Center and University of Washington, Seattle; ${ }^{2}$ Novartis Pharmaceuticals Corporation, East Hanover; ${ }^{3}$ Icahn School of Medicine at Mount Sinai, New York; ${ }^{4}$ Corrona, LLC, Southborough; ${ }^{5}$ University of Massachusetts Medical School, Worcester; ${ }^{6}$ The University of Texas MD Anderson Cancer Center, Houston; ${ }^{7}$ New York University School of Medicine, New York, United States; ${ }^{8}$ University of Leeds, Leeds, United Kingdom

Background: The Psoriasis Epidemiology Screening Tool (PEST) is a 5-item questionnaire developed to help identify psoriatic arthritis (PsA) at an early stage, with a score $>3$ indicative of PsA. ${ }^{1}$ A recent Korean study found that a PEST score of 2 may be a more favorable cutoff for screening patients with psoriasis ( $\mathrm{PsO}$. ${ }^{2}$ Objectives: To assess the risk of undiagnosed PsA among patients with PsO and characterize patients based on PEST scores in a US cohort.

Methods: This study included all patients enrolled in the Corrona PsO Registry with data on all 5 PEST questions. Demographics, disease characteristics, patient-reported outcomes (PROs) and medication use were analyzed at the time of enrollment and stratified by PEST score $(0,1,2$ or $\geq 3)$. Pairwise comparisons were made between PEST score $=0$ (reference) and other PEST score groups using $t$-tests for continuous variables and $\chi^{2}$ tests for categorical variables.

Results: As of June 2016, 99.1\% (1516/1529) of patients in the Corrona PsO Registry had data on all 5 PEST questions; 612 patients $(40.4 \%)$ had dermatologist-reported PsA at enrollment. Among the remaining 904 patients, 421 patients $(46.6 \%)$ had a PEST score $=0,225(24.9 \%)$ had a PEST score $=1,146(16.2 \%)$ had a PEST score $=2$ and $112(12.4 \%)$ had a PEST score $>3$. Of patients with a PEST score $>3$, patients most commonly answered "yes" to "have you ever had a swollen joint (or joints)?" (89\%) and "has a doctor ever told you that you have arthritis?" (86\%). Compared with patients with a PEST score $=0$, patients with a PEST score $>1$ all had a higher BMI, longer duration of $\mathrm{PsO}$, increased family history of PsA, increased prevalence of nail PsO and worse EQ-VAS at enrollment (all $P<0.05$; Table 1). In addition, patients with PEST scores $>2$ were older, more likely to be female, less likely to be employed and had an increased family history of PsO, worse pain and fatigue, worse dermatology-related quality of life and higher percentage impairment of daily activities due to psoriasis at enrollment vs patients with a PEST score $=0$ (all $P<0.05)$. There were no significant differences across PEST scores in affected body surface area or PASI scores.

Conclusions: In this cohort of PsO patients with no diagnosis of PsA, patients with PEST scores $\geq 2$ were significantly different from those with PEST scores $=0$ 
Table 1. Baseline characteristics of patients with PsO and no diagnosis of PsA stratified by PEST score $(0-5)$

\begin{tabular}{|c|c|c|c|c|}
\hline Characteristic ${ }^{*}$ & $\begin{array}{c}\text { PEST Score }=0 \\
n=421\end{array}$ & $\begin{array}{c}\text { PEST Score }=1 \\
n=225\end{array}$ & $\begin{array}{c}\text { PEST Score }=2 \\
n=146\end{array}$ & $\begin{array}{c}\text { PEST Score } \geq 3 \\
n=112\end{array}$ \\
\hline Age, years & $48.0(15.5)$ & $48.5(14.9)$ & $53.7(13.8)^{t}$ & $52.9(14.4)^{t}$ \\
\hline Female, $n(\%)$ & $164(39.0)$ & $103(45.8)$ & $72(49.3)^{\dagger}$ & $62(55.4)^{t}$ \\
\hline Currently employed, $n(\%)$ & $311(74.0)$ & $169(75.1)$ & $81(55.9)^{\dagger}$ & $60(53.6)^{\dagger}$ \\
\hline $\mathrm{BMI}, \mathrm{kg} / \mathrm{m}^{2}$ & $28.8(6.9)$ & $29.7(6.8)^{\dagger}$ & $31.4(7.0)^{\dagger}$ & \\
\hline \multicolumn{5}{|l|}{ Categorical BMI (in $\left.\mathrm{kg} / \mathrm{m}^{2}\right), \mathrm{n}(\%)$} \\
\hline Normal/underweight $(<25.0)$ & $133(31.8)$ & $63(28.1)$ & $22(15.2)^{ \pm}$ & $22(19.8)^{4}$ \\
\hline Overweight $(25.0$ to $<30.0)$ & $145(34.7)$ & $73(32.6)$ & $50(34.5)^{\ddagger}$ & $26(23.4)^{7}$ \\
\hline Obese $(\geq 30.0)$ & $140(33.5)$ & $88(39.3)$ & $73(50.3)^{ \pm}$ & $63(56.8)^{ \pm}$ \\
\hline Family history of PsO, $\mathrm{n}(\%)$ & $13(3.1)$ & $12(5.4)$ & $11(7.5)^{t}$ & $14(12.6)^{\dagger}$ \\
\hline Family history of PSA, $n(\%)^{5}$ & $126(30.1)$ & $85(38.1)^{\dagger}$ & $67(45.9)^{\dagger}$ & $46(41.4)^{\dagger}$ \\
\hline Duration of $\mathrm{Ps} \mathrm{O}$, years & $12.8(12.0)$ & $15.3(13.2)^{\top}$ & $19.1(15.6)^{\dagger}$ & $17.3(14.8)^{\top}$ \\
\hline Nail PsO, n (\%) & $30(7.1)$ & $35(15.6)^{\dagger}$ & $21(14.4)^{\dagger}$ & $24(21.4)^{\dagger}$ \\
\hline BSA, \% involvement & $8.8(12.2)$ & $9.0(12.0)$ & $9.3(13.9)$ & $10.2(13.3)$ \\
\hline PASI $(0.72)$ & $5.5(6.0)$ & $6.1(6.9)$ & $6.2(7.1)$ & $6.3(6.5)$ \\
\hline Pain (VAS 0-100) & $20.1(28.3)$ & $21.5(29.1)$ & $24.2(29.2)^{\dagger}$ & $28.3(30.6)^{\dagger}$ \\
\hline Fatigue (VAS 0-100) & $24.2(27.0)$ & $23.0(25.1)$ & $30.4(28.1)^{\dagger}$ & $41.7(27.8)^{\dagger}$ \\
\hline EQ-VAS (VAS 0-100) & $78.7(19.6)$ & $73.9(22.9)^{\dagger}$ & $73.8(22.4)^{\dagger}$ & $67.0(22.9)^{+}$ \\
\hline DLQI $(0.30)$ & $5.8(6.0)$ & $\frac{10.9(2.9)}{6.6(6.1)}$ & $\frac{10.0(2.4)^{7}}{6.9(5.3)^{\dagger}}$ & $\frac{07.1(2.9)^{7}}{8.1(6.5)^{\dagger}}$ \\
\hline WPAI-GH domain: $\%$ of daily & $14.2(23.3)$ & $14.8(23.4)$ & $17.6(24.9)^{\dagger}$ & $24.0(28.6)^{\dagger}$ \\
\hline \multicolumn{5}{|c|}{ 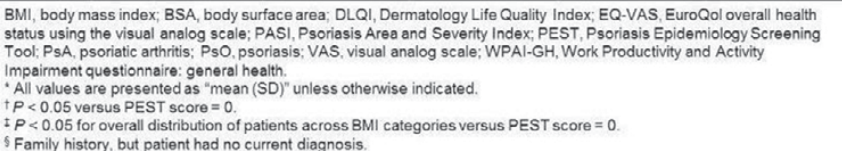 } \\
\hline
\end{tabular}

for many characteristics at enrollment, including BMI and PROs. These findings highlight the value of screening for PsA among patients with PsO in order to potentially improve patient outcomes.

\section{References:}

[1] ) Ibrahim GH, et al. Clin Exp Rheumatol. 2009;27(3):469-74.

[2] ) Ha YJ, et al. Arthritis Rheumatol. 2016;68(suppl 10):A2744

Acknowledgements: The Corrona Psoriasis Registry is sponsored by Corrona, LLC and is funded by AbbVie, Boehringer Ingelheim, Eli Lilly and Company and Novartis Pharmaceuticals Corporation. Corrona, LLC has been supported through contracted subscriptions in the last two years by AbbVie, Amgen, AstraZeneca, BMS, Crescendo, Eli Lilly and Company, Genentech, GSK, Horizon Pharma USA, Janssen, Momenta Pharmaceuticals, Novartis, Pfizer, Roche and UCB.

Disclosure of Interest: P. Mease Grant/research support from: Celgene, Novartis, AbbVie, Amgen, BMS, Lilly, Pfizer and UCB, Consultant for: Celgene, Corrona, Novartis, AbbVie, Amgen, BMS, Crescendo, Genentech, Janssen, Lilly, Merck, Pfizer and UCB, Speakers bureau: AbbVie, Amgen, BMS, Crescendo, Celgene, Genentech, Janssen, Pfizer and UCB, J. Palmer Employee of: Novartis, M. Lebwohl Employee of: Mount Sinai, which received research funds from Amgen, Anacor, Boehringer Ingelheim, Celgene, Lilly, Janssen Biotech, Kadmon, LEO Pharmaceuticals, Medlmmune, Novartis, Pfizer, Sun Pharmaceuticals and Valeant, C. Karki Employee of: Corrona, LLC, G. Reed Shareholder of: Corrona, LLC, Employee of: Corrona, LLC, C. Etzel Consultant for: Merck, Employee of: Corrona, LLC, J. Greenberg Shareholder of: Corrona, LLC, Consultant for: Eli Lilly, Genentech, Janssen, Novartis and Pfizer, Employee of: Corrona, LLC, P. Helliwell Consultant for: Amgen, BMS, Janssen, Lilly, Pfizer and UCB, Speakers bureau: Novartis, AbbVie, Janssen, Lilly, Pfizer and UCB

DOI: 10.1136/annrheumdis-2017-eular.1478

\section{SAT0473 PREVALENCE OF ULTRASOUND ABNORMALITIES IN PATIENTS WITH PSORIATIC ARTHRITIS IN A CLINICAL PHASE OF MINIMAL DISEASE ACTIVITY UNDER ANTI-TNF TREATMENT}

P. Macchioni ${ }^{1}$, G. Ciancio ${ }^{2}$, G. Sandri ${ }^{3}$, A. Zabotti ${ }^{4}$, G. Vukatana ${ }^{5}$ L. Montaguti $^{6}$, M. Focherini $^{7}$, E. Verduci ${ }^{1}$, D. Chessa ${ }^{8}$, M. Govoni $^{2}$ A. Spinella ${ }^{3}$, N. Malavolta ${ }^{5}$, F. Zuliani ${ }^{4}$, M. Bruschi ${ }^{6}$, F. Mascella $^{7}$.

${ }^{1}$ Rheumatology, Arcispedale S Maria Nuova, Reggio Emilia; ${ }^{2}$ Rheumatology, University of Ferrara and Azienda Ospedaliera-Universitaria Sant'Anna, Ferrara; ${ }^{3}$ Rheumatology, University of Modena e Reggio Emilia, Modena: ${ }^{4}$ Rheumatology Clinic, University of Udine, Udine; ${ }^{5}$ Rheumatology, University of Bologna, Bologna; ${ }^{6}$ Rheumatology, Ospedale Bufalini, Cesena; ${ }^{7}$ Medicina Interna e Reumatologia, Ospedale degli Infermi, Rimini; ${ }^{8}$ Internal Medicine, Ospedale Paolo Dettori, Tempio Pausania (OT), Italy

Background: Few studies have analized the persistence of ultrasound (US) abnormalities in patients (pts) with Psoriatic Artritis (PA) during the phase of minimal disease activity (MDA)

Objectives: To investigate the prevalence of US alterations at enthesis, joint and tendon levels in pts with psoriatic arthritis (PA) during a phase of MDA.

Methods: Pts treated with anti-tumor necrosis factor (TNF) for at least 12 months and with at least 6 months duration of MDA were consecutively recruited at 6 Italian centers. In every center, the local rheumatologists provided PA pts to be examined by US. Personal history, demographic and clinical data were recorded. Each patient underwent the following US examinations: metacarpophalangeal (MCP), knee and tibio-tarsal (TT) joint, flexor and extensor tendon of hand digit, flexor and extensor tendon at carpal area, flexor and extensor tendon of foot, and enthesis of common extensor tendon insertion on the lateral epicondyle of the humerus, quadriceps tendon, patellar tendon, Achilles tendon and plantar fascia insertions on the calcaneus. Each examination were performed by rheumatologists expert in US, to assess synovitis (joint effusion, synovial proliferation, and power Doppler (PD) signal), and bone erosions, flexor tendon tenosynovitis, hand finger extensor tendon tenonitis, and enthesel involvement using an Esaote MyLabClass with a 5-13 or 6-18 MHz linear probe. The following elementary lesions were assessed at each enthesis: morphologic abnormalities (hypoechogenicity and/or thickening), entheseal calcific deposits, cortical abnormalities (bone erosion and/or proliferation), adjacent bursitis and intraenthesis and perienthesis (tendon body and/or bursa) PD signal. All US findings were scored using a 4 degree semiquantitative scoring system. US acute enthesitis was defined by the presence of entheseal edema or PD signal. US chronic entheseal alterations by the presence of calcifications, erosions, or enthesophytes. US peripheral active synovitis if synovial hypertrophy was associated with the presence of PD signal. US examinator were blind of clinical data of the pts.

Results: Sixty-three pts were recruited (mean age $53 \pm 13 y$, mean PA duration $13 \pm 8 y$, mean MDA duration $21 \pm 11 \mathrm{~m})$. At US examination $66.7 \%$ of pts had at least one peripheral joint involved (17.5\% had peripheral active synovitis), $47.6 \%$ had acute enthesitis and $95.2 \%$ chronic enthesopathy. US bursitis was present in $22.2 \%$ of pts, $3.7 \%$ had hand extensor finger tendon involvement.

Table 1 shows clinical and demographical data of the pts and table 2 the US results

\begin{tabular}{lcccc}
\hline & Nail involvement & Previous dactylitis & FamHyst & IBP \\
\hline Patients with abnormality (\%) & 28.3 & 42.9 & 23.9 & 19.7 \\
\hline
\end{tabular}

Table 2. US abnormalities in 63 pts in MDA

\begin{tabular}{lccccc}
\hline & $\begin{array}{c}\text { Perypheral } \\
\text { active } \\
\text { sinovitis }\end{array}$ & $\begin{array}{c}\text { Joint } \\
\text { peripheral } \\
\text { involvement }\end{array}$ & $\begin{array}{c}\text { Chronic } \\
\text { entheseal } \\
\text { alterations }\end{array}$ & $\begin{array}{c}\text { Acute } \\
\text { entheseal } \\
\text { alterations }\end{array}$ & Tenosynovitis \\
\hline Patients with abnormality (\%) & 17.5 & 66.7 & 95.2 & 47.6 & 29.6
\end{tabular}

Conclusions: Joint, entheseal and tendon abnormalities have a high prevalence in PA patients treated with anti-TNF during MDA.

Disclosure of Interest: None declared

DOI: 10.1136/annrheumdis-2017-eular.5010

\section{SAT0474 VERY LOW DISEASE ACTIVITY AND IMPACT OF DISEASE IN A SPANISH POPULATION WITH PSORIATIC ARTHRITIS}

R. Queiro, J.D. Cañete, C. Montilla, M.A. Abad, S. Gómez, A. Cábez. Rheumatology, Hospital Universitario Central de Asturias, Oviedo, Spain

Background: The target of treatment in psoriatic arthritis (PsA) should be remission or inactive disease. A potential definition that would fit with the Treatto-Target Recommendations would be MDA meeting all 7 criteria $^{1}$, proposed as a definition of very low disease activity (VLDA) in PsA. Patient reported outcomes (PROs), such as those provided by the novel PSAID questionnaire ${ }^{2}$, are also important to evaluate healthcare interventions and to reflect the impact of PsA on patients' lives.

Objectives: The aims of the present study were to evaluate the prevalence of VLDA in patients with PsA and how much residual active disease is still present, so as to determine whether PSAID could be an additional useful tool to assess PsA interventions in clinical practice.

Methods: This was a post-hoc analysis of data from a cross-sectional observational and multicenter study (MAAPS), aimed at evaluating the prevalence of MDA in a Spanish population with PsA, to describe their characteristics and to evaluate the association between MDA and the impact of the disease as assessed by the PSAID questionnaire in routine clinical practice The original study included adult patients of both genders diagnosed with PsA according to CASPAR criteria with at least one year of evolution time of disease and on treatment with biological and/or conventional synthetic disease modifying anti-rheumatic drugs (cDMARD). Patients were considered in VLDA when they met all the MDA criteria ${ }^{1}$ : tender joint count $\leq 1$, swollen joint count $\leq 1$, Psoriasis Area Severity index (PASI) score $\leq 1$ or body surface area $\leq 3 \%$, patient pain visual analog scale (VAS) score $\leq 15$, patient global disease activity VAS score $\leq 20$, Health Assessment Questionnaire (HAQ) score $\leq 0.5$, and tender entheseal points $\leq 1$. Patient acceptable symptoms state (PASS) has been defined as a PSAID value $<4$.

Results: 227 patients were included, $133(58.6 \%)$ in MDA state and $58(25.6 \%)$ in VLDA state. VLDA patients suffered from a mild impact of the disease according to PsAID: the majority (82.5\%) had a PSAID score $<4$ and a mean total score (SD) of 2.1 (2.6) IC95\% [1.55-2.64], while, 66.7\% of MDA patients had a PSAID score $<4$ and a mean total score (SD) of 3.3 (3.1) IC95\% [2.82-3.87]. Disability, as measured by HAQ was greater in MDA patients (mean (SD) $0.3(0.5)$ IC95\% $[0.21-0.43]$ ) than in those who reached VLDA state (mean (SD) $0.2(0.3)$ IC95\% [0.11-0.25]

Conclusions: $26 \%$ of Spanish PsA patients achieve VLDA state in routine clinical practice. PsA patients who reached this state also had a very low impact of disease according to PSAID. VLDA state could represent a situation of clinical remission in PsA.

References:

[1] Coates LC, Fransen J, Helliwell PS. Ann Rheum Dis 2010;69(1):48-53.

[2] Gossec L, de WM, Kiltz U, Braun J, Kalyoncu U, Scrivo R et al. Ann Rheum Dis 2014;73(6):1012-1019.

Acknowledgements: MAAPS (Minimal Activity in Psoriatic Arthritis) study group: J.C. Torre Alonso; J.A Román Ivorra; J. Sanz; J. Salvatierra; J. Calvo Alén; 